\title{
MODERN STATE OF THE PROBLEM OF DIAGNOSIS OF THYROID NODULES (LITERATURE REVIEW)
}

\author{
Abdurakhmanov D.Sh. ${ }^{1}$, Shamsiev J.Z. ${ }^{2}$ (Republic of Uzbekistan) \\ Email: Abdurakhmanov343@scientifictext.ru
}

\author{
${ }^{I}$ Abdurakhmanov Diyor Shukurullaevich - Resident magistracy, \\ SPECIALTY: SURGERY; \\ ${ }^{2}$ Shamsiev Jasur Zafarovich - Student, \\ MEDICAL FACULTY, \\ SAMARKAND STATE MEDICAL INSTITUTE, \\ SAMARKAND, REPUBLIC OF UZBEKISTAN
}

\begin{abstract}
: the question of modern possibilities of complex diagnostics of nodular formations of the thyroid gland is considered. Despite the large number of studies conducted, it is not always possible to correctly establish the exact morphological diagnosis of thyroid nodules, which indicates the need to improve existing and search for new more informative diagnostic methods. In this respect, reports on the use of tissue pressure measurements in the thyroid glands for differential diagnosis of various pathologies of this organ appear to be very promising. Keywords: thyroid gland, morphological form, nodal formation, thyroid cancer.

\section{СОВРЕМЕННОЕ СОСТОЯНИЕ ПРОБЛЕМЫ ДИАГНОСТИКИ УЗЛОВЫХ ОБРАЗОВАНИЙ ЩИТОВИДНОЙ ЖЕЛЕЗЫ (ОБЗОР ЛИТЕРАТУРЫ)} Абдурахмонов Д.Ш. ${ }^{1}$, Шамсиев Ж.3.² (Республика Узбекистан)

\author{
${ }^{1}$ Абдурахмонов Диёр Шукуруллаевич - резидент магистратуры, \\ специальность: хирургия; \\ ${ }^{2}$ Шамсиев Жасур Зафарович - студент, \\ лечебный факультет, \\ Самаркандский государственный медицинский институт, \\ г. Самарканд, Республика Узбекистан
}

\begin{abstract}
Аннотация: рассматривается вопрос о современных возможностях комплексной диагностики узловых образований шитовидной железы. Несмотря на большое число проведенных исследований не всегда возможно правильно установить точный морфологический диагноз узловых образований щитовидной железы, что свидетельствует о необходимости совершенствования существующих и поиска новых более информативных методов диагностики. В этом отношении сообщения об использовании измерений тканевого давления в щүитовидные железы для дифференциальной диагностики различной патологии данного органа представляются весьма перспективными.
\end{abstract}

Ключевые слова: щитовидная железа, морфологическая форма, узловые образования, рак щитовидной железы.

At present, there is a trend towards an increase in the number of thyroid nodular formations (TNF) [10]. The frequency of detectable nodes in the thyroid gland (thyroid gland) depends on the method of investigation. At palpation of the thyroid gland, nodal formations are found in 4-6\% of the population in areas with a sufficient content of iodine in water and food, in the zones of goiter endemia their prevalence is somewhat higher. With ultrasound thyroid, the frequency of detection of previously unidentified knots in adults is 13-40\%. At autopsy of persons, who died from non-thyroid diseases, nodes in the thyroid gland find more than half of people [3]. The prevalence of thyroid cancer among the nodular formations, thyroid gland, according to different authors, is from 2.4 to $31.4 \%$. According to V.V. Dvoyrina (2001), the growth rate of thyroid cancer over the past decade was 131-133\%, which is significantly higher than other cancer. According to the American Cancer Society, about 17,000 new cases and about 1,300 deaths associated with thyroid cancer are reported annually in the United States. In this regard, the problem of differential diagnosis of thyroid cancer becomes especially urgent [5].

The problem of early diagnosis and timely adequate treatment of pathological formations of the thyroid gland, which today are found in $4-10 \%$ of the population, is still relevant. The incidence of nodal euthyroid diseases ranges from 10 to $62 \%$. Under the term "nodular diseases", the nodal colloid goiter (NTG), adenomas, " pseudo nodes " for chronic autoimmune thyroiditis (CAIT), various morphological variants of the thyroid gland, as well as their combinations. The fact that the prevalence of focal lesions of the thyroid gland is extremely high in many countries of the world, according to numerous studies. So in France, for 1,000 people, an average of $35 \%$ of thyroid nodules, in the USA for 100 people, $21 \%$ (4-7\% of the total population), in Japan for 450 people - 19\%. In Uzbekistan there are an average of $10 \%$ of focal pathology per 2 thousand population [3]. A number of authors noted that the number of focal thyroid lesions increases with age [11]. The main cause of nodal colloid 
goiter is iodine deficiency of various origins. When insufficient intake of iodine to maintain a euthyroid state is amplified products iodinated less, but biologically more active $\mathrm{T}_{3}$, whereas the content of $\mathrm{T}_{4}$ decreases. By the feedback mechanism, secretion of TG increases, which leads to an increase in the number of thyocytes. In addition to TG, there are polypeptides that increase the functional activity and the ability to multiply thyroid cells - " epidermal growth factor", "growth stimulating immunoglobulin", growth hormone. Elevated levels of fluoride and calcium in drinking water lead to the development of nodes in the thyroid. Antithyroid drugs and sulfonamides can also give a creeping effect [4].

The appearance of adenomas and thyroid cancer (thyroid cancer) is a consequence of a disorder in the cell proliferation of thyroid cells. Not the last place in this is allocated to the hereditary predisposition, the effects of ionizing radiation [8]. Identify the thyroid cancer based on only the history and physical examination is difficult. This is due to the fact that most of the thyroid tumors are highly differentiated and do not differ from benign thyroid nodules. Such generally accepted criteria of malignancy, such as rapid node growth and dense consistency, are of little help in the differential diagnosis of benign diseases and thyroid cancer. So, on the one hand, the rapid growth of the node is often observed with hemorrhage to the adenoma, and in persons with thyroiditis Hashimoto in thyroid gland find dense knots, on the other hand the malignant node can be soft upon palpation and last for a long time to exist in the thyroid gland without signs of growth. Such criteria of knot malignancy, as lack of displacement during swallowing, hoarseness of voice, increase of regional lymph nodes, are more specific, but are extremely rare. Meanwhile, clinical data should be taken into account when evaluating the thyroid gland. First of all, those of them that indicate a high risk of malignancy of this node, namely, the age of the patient over 60 years and under the age of 25, male gender, irradiation of the head and neck area in history, knot size exceeding 3-4 cm [9].

The informative value of palpation survey ranges from 35 to $62.5 \%$, and in 25 to $36 \%$ of cases, palpable solitary nodes are multiple when using additional techniques [10]. The analysis shows that in $26-40 \%$ of cases there is a discrepancy between the data of the palpation survey in relation to the number of nodes with operative findings [11]. Reliability of palpation research depends on the size and location of the node, the size and shape of the neck, the experience of the doctor. Along with the generally accepted laboratory tests (general blood test, general urine analysis, biochemical blood test, coagulogram), patients with thyroid cancer need to study the hormonal status. When the patient is diagnosed with UA thyroid, an evaluation of the TG level by a highly sensitive method is shown [7]. If a reduced level of TG is detected, an additional determination is made of the level of free $\mathrm{T}_{4}$ and free $\mathrm{T}_{3}$, if an increased $\mathrm{TG}$ level of free $\mathrm{T}_{4}$ is detected. Determining the level of thyroglobulin, as well as antibodies to thyroid cancer in diagnostic search for nodular goiter is not advisable.

Laboratory methods of diagnosis can clarify the diagnosis of the disease, but do not exclude errors in their interpretation. So, with climax in the blood, there may be an increase in the TG content in the intact thyroid gland. Elevated titer of antibodies to thyroglobulin and peroxidase of thyrocytes can be obtained in patients with nonendocrinediseases when taking drugs that affect the nature of the immune response. The wide introduction of modern instrumental research methods into clinical practice allowed to significantly increase the differential capabilities in diagnosis of thyroid cancer [6]. However, in numerous works contradictory data are presented on the diagnostic value of each of the existing methods, as well as on the possibilities of their combination or sequential application. Until now, the "gold" standard for diagnosis of thyroid gland remains a planned histological study. Timely and accurate diagnosis of thyroid cancer is important in the choice of method of treatment, the scope and nature of surgical intervention. Survey radiography is not significant in the diagnosis of ultrasound and allows you to judge the nature of the lesion only by indirect signs of displacement, retrotracheal space.

Widely used method of pneumothyroidography, which consists in contrasting the thyroid gland by introducing oxygen into the interfascial space of the neck [9]. Direct (changes in the visible contours of the thyroid gland) and indirect signs (displacement and compression of the trachea, esophagus, muscles, large blood vessels) of the thyroid gland were isolated. This method was used for the diagnosis of a retrosternal goiter, nodular forms of goiter [4].

About three decades ago, the first works on the use of thermography in the diagnosis of thyroid diseases appeared. Most of the work was devoted to differential diagnosis of malignant and benign thyroid diseases [5]. However, a number of authors note the fact that there is no correlation between the thermography, the histological structure and the size of the thyroid tumor [2].

Until now, for indirect diagnosis of thyroid gland diseases, indirect percutaneous thyroidulymphography is used. This method allows obtaining additional information on the structure, topography, shape, contours and dimensions of the thyroid gland, to a certain extent assess the intraorganic prevalence of the pathological process, while being fairly simple and accessible [5]. Thyroidulymphography can be used for in vivo study of lymph circulation in the thyroid gland. According to some authors, thyroidulymphography allows judging on the functional state of the thyroid gland on the basis of data on the speed of spreading and excretion of contrast medium [1]. This method makes it possible to visualize small nodal formations more reliably than scanning differential diagnosis between nodular and multinodular goiter helps in the diagnosis of thyroid cancer. 
However, according to M.P. Cherenko (1989) thyroidulymphography is not critical in the diagnosis of thyroid cancer. I.A. The accountant and co-workers. (1987) believe that with the development of cancer in a benign tumor (nodular goiter, adenoma), there are no lymphographic signs of malignancy until the moment the process leaves the capsule. S.A. Sergeev (1985) emphasizes that the thyroidographic criteria for malignancy were reliable only with common malignant lesions and had no practical significance for differential diagnosis. A.Bollo at al. (1959) proposed a method of arteriographyfor the diagnosis of thyroid diseases. A number of researchers used it in the diagnosis of benign and malignant tumors of the thyroid gland. Arteriography in the diagnosis of thyroid diseases has an auxiliary significance and should be carried out according to strict indications only in cases when other methods do not provide the necessary diagnostic information [6].

One of the methods used to examine patients with thyroid cancer is the PHC. The nature of the accumulation of the radiopharmaceutical in the thyroid is determined by its functional activity. The scanogram makes it possible to determine the topography, the shape, the size of the fraction, and also the functional activity of the nodal formations and the parenchyma of the thyroid [3].

It is difficult not to agree with the opinion of a number of researchers that at the present stage of development of thyroidology, the detection of thyroid cancer in radionuclide scanning (RNS) is inadvisable, since the information obtained by the method is not of great diagnostic value. Pre-existing opinion that suspicious for cancer are "cold" nodes that are currently being questioned, as there is evidence that cancers are also able to store pharmaceuticals, cases of detection of cancer are described in functioning, "warm" and hyperfunctioning " hot "nodes. The frequency of malignancy in the "hot knots", according to various authors, is $16-20 \%$. On the other hand, the cancer of thyroid cancer looks like a dysfunctional or "cold" node, most of the "cold" nodes are colloidal in histological research, among them, 15-20\% of the observations are detected [9].

There appeared publications of a number of authors about the successful detection of malignant adenoma of the thyroid gland with simultaneous use of two isotopes - $\mathrm{Th}^{201}$ and $\mathrm{I}^{138}$. At the same time, these authors, as well as most other researchers, do not consider the routine use of RNS for differential diagnosis of thyroid tumors to be expedient. The disadvantages of the method include the need for the introduction of radioactive material into the patient's body, the difficulty in identifying the formation of less than $15 \mathrm{~mm}$, the inability to differentially diagnose malignant and benign nodules, in multinodular euthyroid craw (METC), the interpretation of scansis difficult and is accompanied by the greatest number of errors. However, the use of TN in the long-term period is informative for clarifying the localization of residual and ectopic thyroid tissue, the definition of metastases in regional lymph nodes. Thus, at the present time, scanning is not significant in the differential diagnosis of thyroid cancer [10].

Computed tomography and magnetic resonance imaging methods are expensive, are not available for most patients and not having significant advantages over traditional diagnostic tests - may be used to identify retrosternal goiter, tumor metastasis, for the detection of invasion of adjacent structures at locally advanced cancers [8]. In typical clinical cases, CT and MRT do not have any statistically significant advantages over ultrasound in combination with NAB under ultrasound control [6]. Most researchers, considering the above, do not consider them a method of choice for most thyroid diseases [9].

A preoperative examination of the patient attaches great importance to fine needle aspiration biopsy (NAB). According to the summary data, the overall sensitivity of NAB in diseases of the thyroid gland is $60-94 \%$, specificity reaches $94-100 \%$. The percentage of false negative results varies from 4 to 11 (an average of 5\%), false positive - from 0 to 10 (an average of 3\%). Obtaining adequate cytological material with the help of NAB, according to the literature, is possible in $80-98 \%$ of observations, which largely depends on the experience of a specialist who conducts the specified diagnostic procedure. Some researchers prefer a thick-needle biopsy of the thyroid gland, pointing out its advantages. With the help of this procedure it is possible to obtain a column of tissue for histological examination. Many researchers believe that the effectiveness of NAB and thick-needle biopsy in the. Diagnosis of thyroid disease is approximately the same, but with thicker biopsy, there are more complications.

According to N.I. Nikitina (1972), the coincidence of cytological and histological data in colloid goitre is observed in $75 \%$, in adenomas - in 93\%, in cancer of thyroid cancer - in $100 \%$ of cases. The same data are given in other modern studies. The sensitivity of NAB in the detection of thyroid cancer, according to the majority of authors, is from 10 to $62 \%$. Puncture biopsy allows to establish the diagnosis only in $3 / 4$ of all cases of thyroid cancer. The diagnostic value for follicular cancer is lower (no more than 40\%). It is especially difficult to distinguish follicular adenoma, which is a benign tumor, from follicular cancer in case of puncture biopsy. Therefore, the follicular adenoma, regardless of size and degree of activity, is an indication for surgical intervention. The sensitivity of NAB in METC is reduced compared to the sensitivity of solitary thyroid. The sensitivity of the method, according to different researchers, is $60-94 \%$, specificity reaches $64-86 \%$.

Morphological material obtained with NAB is usually divided into 4 categories: 1) benign changes; 2) malignant changes; 3) suspicious for malignant; 4) insufficient material for research. The disadvantage of NAB is that the manipulation is carried out practically "blindly", relying on the data of palpation. The greatest prospect of the development of visual control during the puncture biopsy of modern researchers see the use of ultrasound. 
NAB with ultrasound guidance allows to increase sensitivity up to $93 \%$, and specificity up to $89 \%$. The preparation of a cytological material in non-palpable thyroid lesions is possible only under the supervision of ultrasound. According to E.I. Trofimova (1997), in a comparative evaluation of the results of cytological examination obtained with puncturenon-palpable nodal formations under the control of ultrasound and a planned morphological study, diagnoses coincided in $77.1 \%$ of observations.

Thus, as the literature data show, pre-operative methods of investigation do not allow establishing a reliable diagnosis in $100 \%$ of cases. In this regard, a great deal of attention is paid to methods of intraoperative diagnostics of thyroid gland.

\section{References / Сиисок литературы}

1. Balabolkin M.I., Klebanova E.M. \& Kreminskaya V.M., 2007. Fundamentalnaya I klinicheskaya tireoidologiya [Fundamental and clinical thyroidology]. Moskow: Medicina [in Russian].

2. Vanushko V.E. \& Fadeyev V.V., 2012. Uzlovoy zob [Nodular goiter]. Endocrine Surgery [in Russian].

3. Daminov F.A. et all, 2013. Khirurgicheskaya taktika lecheniya diffuzno-toksicheskogo zoba [Surgical tactics of treatment diffuse-toxic goiter]. Academic Journal of Western Siberia (Vols. 9). 1. Pp. 21 [in Russian].

4. Zayniyev A.F., Yunusov O.T. \& Suyarova Z.S., 2017. Rezultati kxirurgicheskogo lecheniya bolnikh uzlovim zobom [Results of surgical treatment of nodular goiter]. Education and Science Bulletin. 6 (30) [in Russian].

5. Shulutko A.M., Semikov V.I. \& VeTGev P.S., 2011. Nepalpiruyemiye uzloviye obrazovaniya shitovidnoy zhelezi [Non-palpable nodal formations of the thyroid gland]. Moskow. Profil-2C [in Russian].

6. Yusupov Sh.A. et all, 2017. Otdalenniye rezultati operativnogo lecheniya uzlovikh obrazovaniya shitovidnoy zhelezi [Remote results of surgical treatment of nodular thyroid formations]. Achievements of clinical and experimental medicine. 1 (29). Pp. 80-84) [in Russian].

7. Bolgov M.Y., Taraschenko Y.N. \& Yanchiy I.R., 2014. Results of Long-Term Follow-Up of Patients with Benign Nodules of Thyroid Gland. International Journal of Endocrinology. 2.58. Pp. 9-14 [in Enslish].

8. Kasymov S.Z. \& Davlatov S.S., 2013. Hemoperfusion as a method of homeostasis protection in multiple organ failure syndrome. BBK 51.1 74.58. 22. Pp. 85) [in English].

9. Kasimov S.Z. et al., 2013. Haemosorption in Complex Management of Hepatargia. The International Journal of Artificial Organs. (Vols. 36), 8. Pp. 548 [in English].

10. Malik A. et al., 2014. Hypertension-related knowledge, practice and drug adherence among inpatients of a hospital in Samarkand, Uzbekistan. Nagoya journal of medical science. Vol. 76. 3-4. Pp. 255 [in English].

11. Shamsiyev A.M. \& Khusinova S.A., 2008. The Influence of Environmental Factors on Human Health in Uzbekistan. The Socio-Economic Causes and Consequences of Desertification in Central Asia. Springer, Dordrecht. Pp. 249-252 [in English]. 